\title{
MODEL PENILAIAN SISTEM PENDUKUNG KEPUTUSAN DENGAN MENGGUNAKAN METODE SMART UNTUK PENENTUAN PENDISTRIBUSIAN TENAGA KESEHATAN PADA PUSKESMAS DI KABUPATEN PIDIE
}

\author{
Husaini \\ Fakultas Teknik Informatika Universitas Jabal Ghafur
}

\begin{abstract}
ABSTRAK
Dinas Kesehatan (Dinkes) Kabupaten Pidie sebagai peran penting dalam menjalankan tugas serta fungsi untuk menentukan pendistribusian tenaga kesehatan pada Puskemas, Saat ini terjadi tidak meratanya tenaga kesehatan dan penumpukan serta kekosongan tenaga kesehatan yang terdapat pada 26 (Dua puluh enam) puskesmas-puskesmas yang ada dalam Kabupaten Pidie sudah mencukupi untuk melayani masyarakat. Pada Dinas Kesehatan Kabupaten Pidie saat ini dalam pendistribusian penempatan tenaga kesehatan sudah menggunakan komputer namun belum menggunakan suatu sistem. Dalam hal pendistribusian Tenaga kesehatan pada Puskesmas perlu merancang sebuah sistem pendukung keputusan penentun pendistribusian tenaga kesehatan pada puskesmas yang ada di Kabupaten pidie. Pendistribusian penempatan yang dilakukan dengan sistem ini yaitu dengan menggunakan beberapa kriteria penilaian juga dengan beberapa model baik rancangan mupun output. Dengan sistem ini sangat membntu Dinas Kesehatan dalam pendistribusian penempatan tenaga kesehatan pada puskesmas yang tersebar dalam Kabupaten Pidie, Sehingga tidak terjadi penumpukan pada suatu puskesmas kekosongan tenaga kesehatan juga salah dalam penempatan bidang keahlian tenaga Kesehatan.
\end{abstract}

Kata kunci : Model Penilaian, Penentuan Pendistribusian Tenaga Kesehatan, Metode Smart, Kriteria.

\section{Pendahuluan}

Puskesmas adalah suatu unit pelayanan kesehatan yang merupakan ujung tombak dari pelaksanaan program kesehatan berfungsi untuk memberikan pelayanan secara merata kepada masyarakat, oleh karena itu mutu pelayanan diberikan sebaiknya sesuai dengan program kesehatan. Dalam Kabupaten pidie saat ini terdapat 26 (Dua puluh enam) puskesmas yang terdapat dalam setiap kecamatan. Namun demikian sejumlah puskesmas yang ada saat ini di Kabupaten Pidie masih terkendala dalam memberikan pelayanan kepada masyarakat pada saat kunjungan pasien, hal tersebut karena tenaga kesehatan yang ada disetiap Puskesmas belum merata, sebagai contoh pada satu puskesmas lokasinya jauh dengan kota Kabupaten sehingga tenaga kesehatan yang ada dipuskesmas tersebut sangat minim, sementara jumlah penduduk pada lokasi tersebut masyarakatnya banyak penyebab minimnya tenaga kesehatan pada puskesmas tersebut karena tempat tinggal tenaga kesehatan dengan tempat dia bekerja jarak lokasi terlalu jauh sehingga tenaga kesehatan tersebut pindah alasan jauh dengan rumah tempat tinggal.

Faktor tidak meratanya tenaga kesehatan berdasarkan bidang atau keahlian yang dimiliki oleh setiap tenaga kesehatan tersebut, sebagai contoh tidak semua puskesmas memiliki tenaga kesehatan berdasarkan ahli dibidang penyakit yang dikunjungi oleh masyarakat, sehingga dalam penanganan pasien bukan bidang keahlian atau spesialis yang dimiliki oleh seorang tenaga kesehatan terutama sekali puskesmas yang jarak lokasi dengan kota Kabupaten dalam hal ini perlu Dinas kesehatan mendistribusikan tenaga kesehatan pada puskesmas berdasarkan bidang keahlian. 
Dalam hal ini perlu dikaji ulang agar dalam pendistribusian tenaga kesehatan yang ada dikabupaten pidie tepat sasaran. Untuk mendata kembali jumlah tenaga kesehatan yang ada pada setiap puskesmas perlu menggunakan suatu sistem untuk menentukan jumlah tenaga kesehatan berdasarkan jumlah kunjungan masyarakat disetiap puskesmas sehingga pelayanan lebih memuaskan. Dengan menggunakan sistem pendukung keputusan ini pemerataan tenaga kesehatan yang ada dikabupaten pidie khususnya pada puskesmas sudah maksimal sehingga program pemerintah dalam memberikan pelayanan bagi kunjungan pasien sudah tercapai.

\section{Kajian Pustaka}

Sistem pendukung keputusan diartikan sebagai suatu sistem informasi berbasis computer yang menghasilkan berbagai alternatif keputusan untuk membantu manajemen dalam menangani berbagai permasalahan yang terstruktur ataupun tidak terstruktur dengan menggunakan data dan model. (Dadan Umar Daihani (2001).

Definisi model menurut McLeod (1995) dalam bukunya sistem informasi manajemen adalah penyerdehanaan (Abstraction) dari sesuatu, sedangkan menurut Turban (1998) dalam bukunya Decision Support system And Intelegent Sistems adalah sebuah referensi atau abstraksi realitas yang disederhanakan karena realitas terlalu komplek untuk ditiru secara cepat dan karena banyak dari kompleksitas itu sebenarnya tidak relevan dalam penyelesaian masalah yang spesifik.

Reperansi sistem atau masalah berdasarkan model dapat dilakukan dengan berbagai macam tingkat abstaksi, oleh karena itu model diklasifikasikan menjadi tiga kelompok model menurut tingkat abstraksinya (Turban, 1998).

\section{Model ikonik (skala)}

Sebuah model ikonik, model abstraksi terkecil adalah replica fisik sebuah sistem, biasanya pada suatu skala yang berbeda dari aslinya, model ikonik dapat muncul pada tiga dimensi (miniature maket), sebagaimana pesawat terbang, mobil, jembatan, atau alir produksi, photografi adalah jenis model skala ikonik yang lain, tetapi hanya dalam dua dimensi.

\section{Model Analog}

Sebuah model yang tampak tidak mirip dengan model aslinya, tetapi bersifat seperti sistem aslinya, model analog lebih abstrak dari model ikonik dan merupakan reperansi simbolik dari sebuah entitas. Model ini biasanya berbentuk bagan atau diagram dua dimensi, dapat berupa model fisik, tetapi bentuk model berbeda dari bentuk sistem nyata. Berikut beberapa cntoh lain adalah :

- Badan organisasi yang mengambarkan hubungan struktur otoritas, dan tanggung jawab.

- Sebuah peta dimana warna yang berbeda menunjukkan obyek yang berbeda misalnya sungai atau penggunungan, artinya memberikan perbedaan yang sangat jauh.

- Bagan pasar model yang menunjukkan pergerakan saham.

- Cetak baru dari sebuah atau rumah.

\section{Model Matematik}

Kompleksitas hubungan pada banyak system organisasional tidak dapat disajikan secara model ikon atau model analog atau representasi semacam itu bahkan dapat menimbulkan kesulitan dan membutuhkan banyak waktu dalam pemakaiannya. Oleh karena itu model yang tepat dideskripsikan dengan model matematik. Sebagian besar analisis sistem pendukung keputusan dilakukan secara numerik dengan model matematik atau model kwantitatif yang lain

\section{Metode Penelitian}

Adapun metode penelitian yang dilakukan penulis dalam membangun Model penilaian penentuan penempatan tenaga kesehatan pada puskesmas di Kabupaten Pidie dengan dua cara yaitu :

\section{Pengumpulan Data}

Studi kepustakaan yaitu penelusuran informasi kepustakaan baik mengenai Sistem Pendukung Pengambilan Keputusan 
maupun peraturan-peraturan pemerintah yang terkait dengan Pendistribusian tenaga kesehatan serta peranturan Kementrian Dinas Kesehatan. Wawancara dan observasi dengan mencari dan mengumpulkan datadata yang ada relevansinya dengan penelitian ini pada Dinas Kesehatan Kabupaten Pidie.

\section{Perancangan Sistem}

Merancang database, desain tabeltabel yang diperlukan dalam sistem ini, implementasi dan pengujian terhadap Model penilaian Sistem Pendukung Keputusan Penentuan pendistribusian tenaga kesehatan yang membutuhkan pelayanan bagi masyarakat.

Merancang model-model form dalam penginputan data dengan secara matematis juga dengan model-model kuantitatif, penulis dalam perhitungan penilaian kebutuhan Tenaga kesehatan pada setiap puskesmas, Lokasi distribusi puskesmaspuskesmas yaitu dengan memberi bobot angka terhadap kriteria-kriteria penilaian yang spesifik untuk penentuan tenaga kesehatan pada Puskesmas dalam Kabupaten Pidie.

\section{Metode Smart}

SMART ( Simple Multi Attribute Rating Technique ) merupakan metode pengambilan keputusan yang multiatribut yang dikembangkan oleh Edward pada tahun 1977. Teknik pembuatan keputusan multiatribut ini digunakan untuk mendukung pembuat keputusan dalam memilih antara beberapa alternatif. Setiap pembuat keputusan harus memilih sebuah alternatif yang sesuai dengan tujuan yang telah dirumuskan. Setiap alternatif terdiri dari sekumpulan atribut dan setiap atribut mempunyai nilai-nilai. Nilai ini dirata-rata dengan skala tertentu. Setiap atribut mempunyai bobot yang menggambarkan seberapa penting dibandingkan dengan atribut lain. Pembobotan dan pemberian peringkat ini digunakan untuk menilai setiap alternatif agar diperoleh alternatif terbaik. Pembobotan pada SMART ( Simple Multi Attribute Rating Technique ) menggunakan skala antara 0 sampai 1, sehingga mempermudah perhitungan dan perbandingan nilai pada masing-masing alternatif. Model yang digunakan dalam SMART (Simple Multi Attribute Rating Technique) yaitu :

$$
u\left(a_{i}\right)=\sum_{J=1}^{m} w_{j} u_{i}\left(a_{i}\right), \quad i=1,2, \ldots m
$$

Keterangan:

$w_{j}=$ nilai pembobotan kriteria ke- $\mathrm{j}$

dan $k$ kriteria

$$
u\left(a_{i}\right)=\text { nilai utility kriteria ke-i untuk }
$$

kriteria ke-i

Pemilihan keputusan adalah

mengidentifikasi mana dari $\mathrm{n}$ alternatif yang mempunyai nilai fungsi terbesar.

\section{Model Penilaian Pendistribusian Tenaga Kesehatan}

Model Penilaian yang dilakukan Penentuan; tenaga kesehatan pada puskesmas di Kabupaten Pidie, dapat dilihat pada gambar 1 .

Model penilaian untuk menentukan jumlah nilai keseluruhan dan nilai rata-rata yang diperoleh. Model penilaian untuk menentukan jumlah nilai keseluruhan dan nilai rata-rata yang diperoleh.

Jumlah Nilai = Nilai Lokasi+Nvilai Status perkawinan+Usia Tenaga kesehatan+ Masa kerjatenagakesehatan

\section{Gambar 1. Model Penilaian}

\section{Nilai Jarak Lokasi}

Model nilai jarak lokasi ini yaitu untuk mencari jarak lokasi dengan tempat tinggal Tenaga kesehatan, Untuk lebih jelasnya dapat dilihat pada tabel.1.

Tabel 1 model penilaian jarak lokasi

\begin{tabular}{|c|l|c|c|}
\hline No & Kriteria Lokasi & Skor & Bobot \\
\hline 1 & Jarak 5 KM & 100 & \\
\hline 2 & Jarak 15 KM & 80 & $35 \%$ \\
\hline 3 & Jarak 25 KM & 60 & \\
\hline 4 & Jarak 45 KM & 50 & \\
\hline
\end{tabular}

Nilai Jarak lokasi $=$ Skor $*$ Bobot 


\section{Nilai Status Perkawinan}

Model nilai status perkawinan, pada model ini penilaiannya lebih diutamakan tenaga kesehatan yang statusnya belum kawin, jika dibandingkan dengan yang sudah kawin. untuk lebih jelasnya dapat dilihat pada tabel.2.

Tabel 2 Model Penilaian status

\begin{tabular}{|c|l|c|c|}
\hline No & $\begin{array}{c}\text { Kriteria status } \\
\text { perkawinan }\end{array}$ & Skor & Bobot \\
\hline 1 & Belum Kawin & 100 & $20 \%$ \\
\hline 2 & kawin & 50 & \\
\hline
\end{tabular}

Nilai Status perkawinan $=$ Skor $*$ Bobot

Nilai Usia tenaga kesehatan

Model usia tenaga kesehatan penilaiannya dalam pendistribusian tenaga kesehatan pada puskesmas-puskesmas lebih di utamakan usia yang masih muda, mengingat dalam melaksanakan tugas lebih cepat, penilaiannya lebih tinggi jika dibandingkan dengan usia 40 tahun keatas. untuk lebih jelasnya dapat dilihat pada tabel.3.

Tabel 3 model penilaian usia tenaga kesehatan

\begin{tabular}{|c|l|c|c|}
\hline No & $\begin{array}{c}\text { Kriteria Usia } \\
\text { Tenaga Kesehatan }\end{array}$ & Skor & Bobot \\
\hline 1 & Usia 25-30 & 100 & \\
\hline 2 & Usia 31-40 & 70 & $25 \%$ \\
\hline 3 & Usia 41-50 & 50 & \\
\hline
\end{tabular}

Nilai Usia tenaga kesehatan $=$ Skor $*$ Bobot

\section{Nilai Masa Kerja Tenaga kesehatan}

Model masa kerja Tenaga kesehatan dalam pendistribusian pada puskesmaspuskesmas maksimal diambil lima tahun, jika masa kerja tenaga kesehatan 5 tahun maka nilainya lebih tinggi dan dianggap sudah punya pengalaman dibidang pelayanan, untuk lebih jelasnya dapat dilihat pada tabel.4.
Tabel 4. model masa kerja tenaga kesehatan

\begin{tabular}{|c|lr|c|c|}
\hline No & \multicolumn{2}{|c|}{$\begin{array}{l}\text { Kriteria masa } \\
\text { kerja tenaga } \\
\text { kesehatan }\end{array}$} & Skor & Bobot \\
\hline 1 & $\begin{array}{l}\text { Masa kerja 5 } \\
\text { Tahun }\end{array}$ & 100 & \\
\hline 2 & $\begin{array}{l}\text { Masa kerja } \\
\text { Tahun }\end{array}$ & 80 & \\
\hline 3 & $\begin{array}{l}\text { Masa kerja } \\
\text { Tahun }\end{array}$ & 50 & $20 \%$ \\
\hline 4 & $\begin{array}{l}\text { Masa kerja r 1 } \\
\text { Tahun }\end{array}$ & 20 & \\
\hline
\end{tabular}

Nilai Masa kerja $=$ Skor $*$ Bobot

Data Flow Diagram (DFD) Model Penilaian Sistem Pendukung Keputusan Pendistribusian Tenaga Kesehatan Kabupaten Pidie.

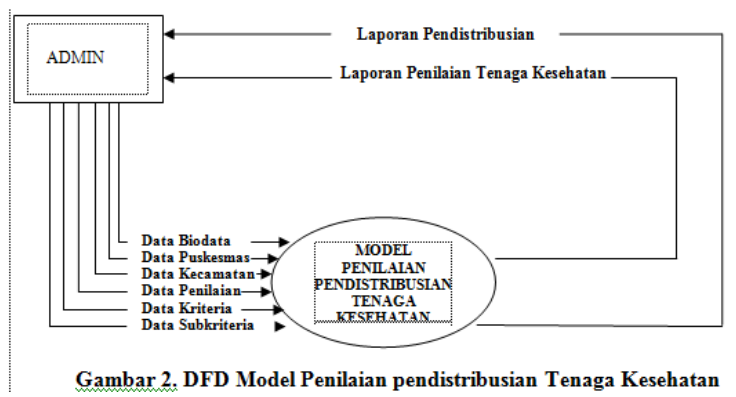

\section{Rancangan Basis Data}

Rancangan basis data merupakan serangkaian pertanyaan spesifik yang relevan dengan berbagai pemrosesan data, misalnya objek data yang akan diproses oleh sistem, komposisi masing-masing objek data dan atribut yang menggambarkannya serta bagaimana hubungan antara masing-masing objek data tersebut.

Data yang akan digunakan Pada Model Penilaian Penentuan Penempatan Tenaga Kesehatan pada Puskesmas diKabupaten Pidie disimpan dalam basis data, basis data dirancang agar mudah dan terorganisir dengan baik sehingga memudahkan dalam pencarian dan manipulasi data.

\section{Entity Relationship Diagram (ERD)}

Penentuan Pendistribusian Tenaga Kesehatan pada puskesmas dapat dilihat pada gambar 3 . 


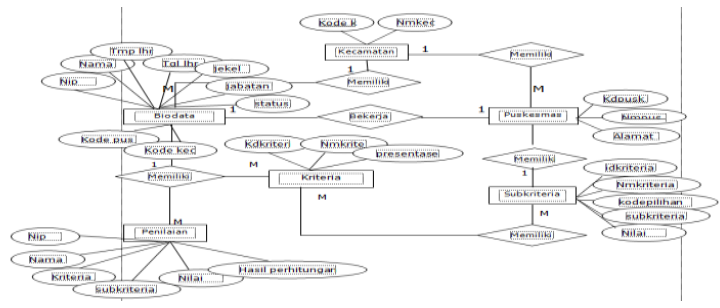

Gambar 3. Entity Relationship Diagram Penilaian Tenaga Kesehatan

\section{Implementasi dan Pengujian sistem}

Untuk menjalankan sistem ini langkah yang dilakukan yaitu dengan mengisi user name dan memasukan passwod untuk lebih jelas dapat dilihat pada gambar 4.1.

Form Login ke sistem

Gambar 4.1 Entri login ke sistem.

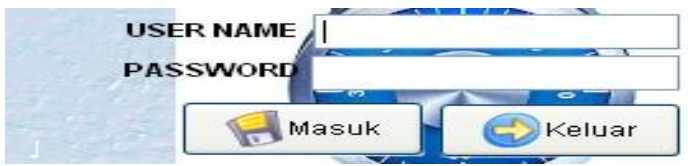

Gambar 4.1 Login ke sistem

\section{Form Entri data Tenaga kesehatan}

Gambar 4.2 Entri data Biodata Tenaga Kesehatan.

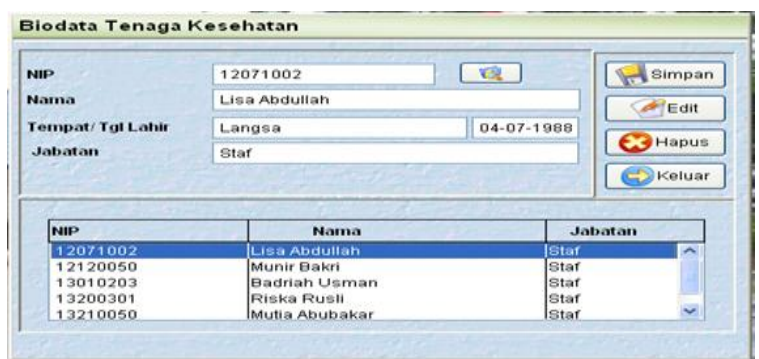

Gambar 4.2 Form entri data tenaga kesehatan

\section{Form Entri data puskesmas}

Gambar 4.3 Entri Data Puskesmas

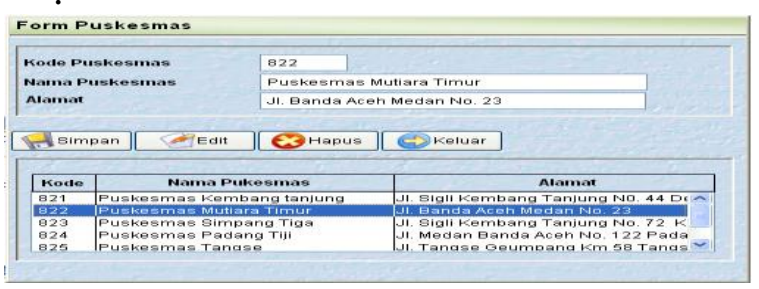

\section{Form Entri data kriteria}

Gambar 4.4 Form Entri Kriteria Tenaga Kesehatan

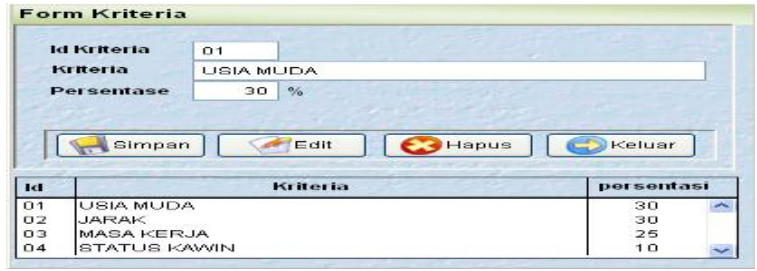

Gambar 4.4. Form Entri data kriteria

\section{Form Entri data penilian}

Gambar 4.5 Entri Data Penilaian Tenaga Kesehatan

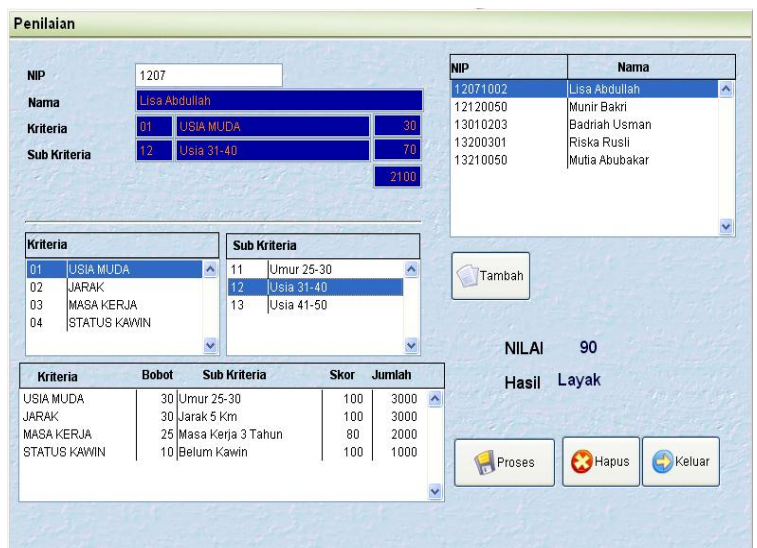

Gambar 4.5 Form Entri Data penilaian Tenaga Kesehatan

\section{Laporan}

Gambar 4.6 Laporan Tenaga kesehatan keseluruhan

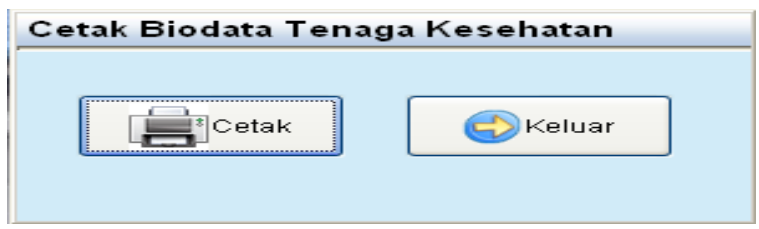

DAFTAR TENAGA KESEHATAN PADA KABUPATEN PIDIE

\begin{tabular}{|c|c|c|c|c|}
\hline \multicolumn{2}{|c|}{ Ilomor } & \multirow{2}{*}{ Hama Penaga Kesehatan } & \multirow{2}{*}{ Tempat / Tanggal lahir } & \multirow[b]{2}{*}{ Jabatan } \\
\hline Urt. & IIIP & & & \\
\hline 1 & 13010203 & Badriah Dgman & Garut 10-10-1986 & Staf \\
\hline 2 & 13200301 & Riska Rusli & Lutiara Timur 11-11-1987 & Staf \\
\hline 3 & 13210050 & Ilutia dbubakar & \begin{tabular}{|l} 
Padang Tiji 09-01-1983 \\
\end{tabular} & Staf \\
\hline 4 & 12071002 & Lisa dhoullah & Langga 04-07-1988 & Staf \\
\hline 5 & 12120050 & Ilunir Bakri & Sigli $07-02-1990$ & Staf \\
\hline
\end{tabular}

Gambar 4.6. Laporan Data Tenaga Kesehatan secara keseluruhan

Laporan berdasarkan hasil penilaian setiap Tenaga kesehatan

Gambar 4.7 Hasil Penilaian Tenaga Kesehatan.

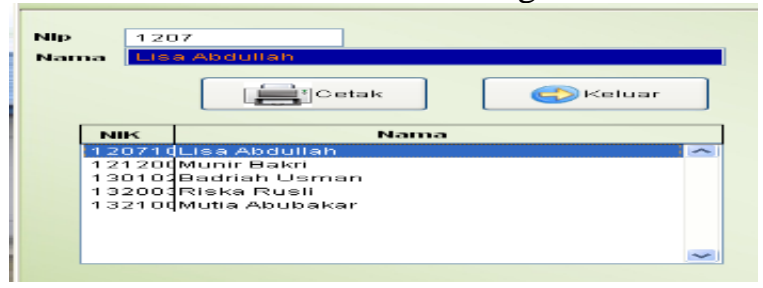




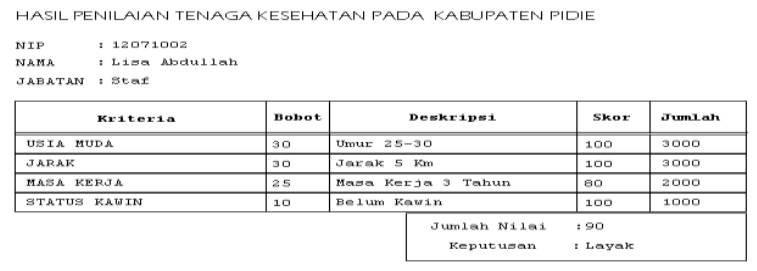

HASIL PENILAIAN TENAGA KESEHATAN PADA KABUPATEN PIDIE

$$
\text { NIP } \quad: 12120050
$$

NAMA : Munir Bakri

JABATAN : Staf

\begin{tabular}{|c|c|c|c|c|}
\hline Kriteria & Bobot & Deskripsi & Skor & Junlah \\
\hline USIA MUDA & 30 & Usia $31-40$ & 70 & 2100 \\
\hline JARAK & 30 & Jarak $25 \mathrm{Km}$ & 60 & 1800 \\
\hline MASA KERJA A & 25 & Masa Kerja 1 Tahun & 20 & 500 \\
\hline STATUS KAWIN & 10 & Kawin & 50 & 500 \\
\hline & & $\begin{array}{l}\text { Jumlah Nilai } \\
\text { Keputusan }\end{array}$ & $\begin{array}{l}: 49 \\
: \text { Tidak }\end{array}$ & \\
\hline
\end{tabular}

\section{Kesimpulan}

Penggunaan Model Penilaian Sistem Pendukung Keputusan Penentuan Pendistribusian tenaga kesehatan ini akan memberi keuntungan kepada Dinas Kesehatan Kabupaten Pidie dalam pendidstribusian tenaga kesehatan pada setiap puskesmas yang ada pada setiap Kecamatan

Model Penilaian Sistem Pendukung Keputusan Pendistribusian Penentuan Tenaga kesehatan ini dapat memproses tenaga kesehatan yang layak juga yang tidak layak yang telah ditentukan dalam model pembobotan nilai,Untuk pengembangan sistem ini sangat mudah.

\section{Daftar Pustaka}

Afrawi, (2011) Sistem Pendukung keputusan penentuan pendistribusian Sekolah Madrasah Snawiyah pada Departemen Agama Kabupaten Pidie.

Little (Dadan Umar Daihani, 2001), Pengertian Sistem Pendukung Keputusan, Edisi I Pengantar , Penerbit Jakarta Pusat, PT. Pustaka Binaan Presindo.

McLeod, R.Jr.,1995, Management Information System, $6^{\text {th }}$ Ed., Prentice Hall.Inc, New Jersey,.

Turban,E;Jay E.A.,2005, Decision Support System and Intelligent System, Fifth edition, Prentice Hall Internasional, Incv.New Jersey

Peraturan Pemerintah Nomor 9 Tahun 2003 Tentang Wewenang Pengangkatan, Pemindahan dan Pemberhentian Pegawai Negeri Sipil.

Depkes RI (2013) Keputusan menteri kesehatan no. 004/MENKES/SK/1/2013 Tentang kebijakan dan strategi bidang kesehatan. Jakarta: Depkes RI 